Cad. Benjaminianos, Belo Horizonte, v. 14, n. 1, p. 73-85, 2018

\title{
Amos Oz e Avraham B. Yehoshua à luz de Walter Benjamin
} Amos Oz and Avraham B. Yehoshua in the light of Walter Benjamin

\section{Juliano Klevanskis Candido}

Universidade Federal de Minas Gerais (UFMG), Belo Horizonte, Minas Gerais / Brasil literatices@yahoo.com.br

Resumo: Este artigo analisa os contos "O caminho do vento" e o "O nômade e a víbora", publicados por Amos Oz em 1965, e o conto "O casamento de Gália”, publicado por Avraham B. Yehoshua em 1970, à luz de alguns aspectos teóricos postulados por Walter Benjamin como "alegoria", "narrativa", "obra épica", entre outros. Os três textos surgem no Brasil na coletânea O novo conto israelense (1978), organizado por Rifka Berezin. Nas narrativas é possível vislumbrar algumas imagens surrealistas e expressionistas, bem como um sentido de personagem moderno que demonstra a crise do homem no século XX, tal como proposto por Benjamin. Como isso acontece em um só texto? As reflexões sobre os contos de $\mathrm{Oz}$ e de Yehoshua, lidos à luz de Walter Benjamin e de suas proposições sobre a vanguarda europeia, se revelam apropriadas, assim, para se avaliar essas e outras questões presentes nas narrativas.

Palavras-chave: Amos Oz; Avraham B. Yehoshua; Walter Benjamin.

Abstract: This article examines the short stories "The way of the wind" and "Nomad and viper", published by Amos Oz in 1965, and the short story "Gallia's wedding", published by Avraham B. Yehoshua in 1970, in the light of some theoretical aspects postulated by Walter Benjamin as "allegory", "narrative", "epic work", among others. The three texts appeared in Brazil in O novo conto israelense (1978), organized by Rifka Berezin. The narratives show some surrealist and expressionist images, as well as a sense of modern character that demonstrates the crisis of man in the 20th century, as proposed by Benjamin. How does it happen in a single text? The reflections on the tales of $\mathrm{Oz}$ and Yehoshua, read in the light of Benjamin's propositions on the European vanguard, are appropriate, therefore, to evaluate these and other issues present in the narrative.

Keywords: Amos Oz; Avraham B. Yehoshua; Walter Benjamin. 
Este trabalho pretende analisar os contos "O caminho do vento" e "O nômade e a víbora", publicados por Amos Oz, em 1965, e "O casamento de Gália", publicado por Avraham B. Yehoshua, em 1970, à luz de aspectos teóricos postulados por Walter Benjamin. No Brasil, esses contos foram publicados na coletânea $O$ novo conto israelense, organizada por Rifka Berezin em 1978. ${ }^{1}$ Nesses textos, é possível vislumbrar algumas imagens que parecem aproximar os escritores israelenses de uma estética da vanguarda europeia, principalmente a expressionista e a surrealista.

Berezin divide a literatura israelense em três gerações. A primeira, dos anos 1930, é representada por Shmuel Yossef Agnon (1888-1970) e Haim Hazaz (1898-1973). Essa geração, denominada Palmach, é composta, sobretudo, por imigrantes europeus com ideias sionistassocialistas que tematizaram a vida no país, tendo o hebraico como segunda língua e profundo conhecimento da literatura de cunho religioso (BEREZIN, 1978, p. 9). A segunda geração, estudada por Berezin, é a da Terra, representada por Aharon Megged (1920-2016) e Yoram Kaniuk (1930-2013) e marcada pela criação de Israel, em 1948. Essa geração expressou suas experiências em hebraico, em uma literatura marcada por "distanciamento da religião, dos valores sociais da diáspora, do schtetl e a aversão à imagem do judeu da diáspora" (BEREZIN, 1983, p. 10). A terceira é a Geração do Estado, composta por sabras, ou seja, judeus nascidos em Israel e educados em hebraico, cuja expressão literária tende ao individualismo, à introspecção e ao subjetivismo, "com abundante emprego de alegorias e frequente alusão a símbolos e mitos" (BEREZIN, 1978, p. 10). Os autores desse grupo focalizam, de acordo com Berezin, os problemas do judeu vítima da Shoah e os conflitos da sociedade israelense e tratariam "de problemas de amor e sensualismo, de tédio, de solidão, de estranhamento e do homem sem raízes" (BEREZIN, 1978, p. 10).

\footnotetext{
${ }^{1}$ Os contos aqui analisados fazem parte da coletânea $O$ novo conto israelense (1978), organizado por Rifka Berezin e traduzido pela equipe de professores da FFLCH da USP: Ana Szpiczkowski, Cecilia K. Schnaider, Cléa Tanai Salzstein, Dezi Siamban, Dora F. Blatyta, Eliana Langman, Ester A. Dimenstein, Fani Stein, Frida G. Spiewak, Ilda Apor, Luba Kignel, Rosilda L. Rozenchan, Miriam Rattner, Nancy Rozenchan, Nora Rosenfeld, Rifka Berezin, Rosely Mandelman, Sônia W. Boguchwal, Suely Dinah Goldstein.
} 
Os judeus tiveram contato com as vanguardas europeias e possivelmente as trouxeram à literatura hebraica, pois, segundo Alan Mintz, houve uma tradição expressionista na literatura ídiche, com Moyshe Kulbak e Yaakov Shteinberg (PINSKER, 2010). Mintz considera a poesia hebraica de Uri Tzvi Greenberg (1894-1981) especialmente influenciada pelo Expressionismo Alemão (MINTZ, 2003, p. 15). E Aminadav Dykman vai além ao considerar Greenberg e Avraham Shlonsky não apenas influenciados pelo Romanticismo Europeu Central, mas também pelo Simbolismo Russo, Expressionismo Alemão e Futurismo Soviético (MINTZ, 2003, p. 73).

Para Benjamin, a arte de narrar estava definhando porque a sabedoria, que denominou de "lado épico da verdade", estaria em extinção (BENJAMIN, 1994, p. 201). E Benjamin imaginava a essência das coisas nos próprios objetos (BENJAMIN, 2009, p. 15). O crítico escreveu inúmeros ensaios que se tornaram clássicos para a refletir sobre a crise de narrar, fruto da pobreza de experiência transmissível. Em 1936, ele apontou para a "voz do narrador nato" (BENJAMIN, 1985, p. 55), e considerou que "entre as narrativas escritas, as melhores são as que menos se distinguem das histórias orais contadas pelos inúmeros narradores anônimos" (BENJAMIN, 1985, p. 198). O crítico defendeu a anulação ou $\mathrm{o}$ aniquilamento da individualidade do narrador em nome da tradição oral.

De acordo com Benjamin, as obras expressionistas deformam a realidade e revelam o lado pessimista da vida. Há aqui a "aspereza acumulada de seus materiais, a presença incondicional do detalhe político, o predomínio do elemento material", o que denominou de Barroco (BENJAMIN, 1986, p. 98). Parte de sua análise incidia sobre a insurgente literatura russa soviética, que "à semelhança dos atuais surrealistas franceses, apresentam uma sequência de imagens desconexas, [...] tais como aparecem, por exemplo, nos sonhos" (BENJAMIN, 1986, p. 102).

E para Karl Pressler, a "grande contribuição de Benjamin na caracterização da modernidade é a retomada da alegoria como conceitochave. Esse conceito não foi elaborado no ensaio sobre o surrealismo, mas no livro sobre o drama barroco alemão e nos ensaios em torno de Baudelaire" (PRESSLER, 1998, p. 128). Para ele, "Benjamin era o único autor alemão que percebeu a importância do surrealismo e adaptou sua maneira de pensar que visava um conhecimento não limitado ao racional" (PRESSLER, 1998, p. 137). 
Benjamin lidou com a produção literária soviética no início do século XX. Israel não estava em sua visão. Mas um de seus tantos questionamentos era em que medida um escritor pode estar ligado a um projeto político sem comprometer sua autonomia? Autonomia da escrita em relação à sociedade representa liberdade de pensamento. Talvez a análise de contos do século XX devesse eliminar desta época o caráter de período concluso, de passado definitivo, daquilo que literalmente se tornou história. Seus meios de produção e formas de vida não se reduzem àquilo que foram naquele tempo e lugar, no interior do modo de produção dominante; Benjamin igualmente via neles em plena função o imaginário de um inconsciente coletivo que ultrapassou em sonhos seus limites históricos, já atingindo o presente, transpondo do indivíduo para o coletivo, onde é multifacetada e fragmentada. Nesse conjunto, seria adequado dizer que a obra de Yehoshua ou a de Oz "prepara uma saudável alienação do homem com relação a seu mundo ambiente" (BENJAMIN, 1987, p. 102) assim como foi, para Benjamin, as literaturas surrealista e expressionista?

Em "O nômade e a víbora", os habitantes de um Kibutz - fazenda coletiva baseada na posse comum da propriedade e dos meios de produção - são surpreendidos pela chegada de beduínos assolados pela fome. Aparecem casos de furto de objetos e de produtos da colheita. Os kibutznikim - residentes em Kibutz - não sabem como enfrentar o problema e a polícia é acionada. Mas esta mostra-se incapaz de identificar os ladrões. No conto, as etnias parecem não se entender. Vários kibutznikim jovens querem responder com violência.

No conto podemos perceber, em primeiro lugar, o choque cultural entre beduínos e habitantes do kibutz como consequência do processo de migração: "Seus rebanhos escuros invadem os campos amarelo-dourados, devorando a palha da colheita ceifada com dentes fortes e vingativos. Os movimentos dos nômades são furtivos e contidos; recuam diante de olhos vigilantes" (OZ, 1978b, p. 51).

A partir da origem genuinamente campesina dos beduínos, $\mathrm{Oz}$ mostra ao leitor a incapacidade dos habitantes do kibutz em negociar com os árabes. Oz propõe que se indague a maneira como os israelenses percebem os árabes, em "Você se aproxima dele e lança-lhe a sua sombra agressiva. Surpreendido, você constata que seus olhos estavam abertos" (OZ, 1978b, p. 51), e em "Não achamos senão pegadas de gente e de animais nos canteiros de legumes" (OZ, 1978b, p. 53). 
A convivência entre os povos é posta em xeque. Os beduínos são considerados árabes genuínos, vivem no deserto, falam língua árabe,

[e] ainda tem as suas canções toda a noite. Uma espécie de lamento melancólico e prolongado paira à noite no ar, desde o pôr-do-sol até a madrugada. As vozes penetram até os confins do Kibutz e oprimem nossas noites com um vago mal-estar. Mal a gente se deita para dormir e o rufar de um tambor distante marca o compasso do nosso sono, como as batidas de um coração relutante (OZ, 1978b, p. 53).

$\mathrm{Oz}$, igualmente, propõe que se indague o universo do kibutz. Como fenômeno espacial, o kibutz é uma colônia agrícola coletiva baseada na posse comum da propriedade, mas externamente precisa de guarda armada e de segurança; assim, o conto fornece um quadro de insegurança a partir da ineficácia das medidas tomadas pelo Estado para supostamente defender o kibutz das ações dos beduínos:

A febre aftosa veio do deserto trazida pela saliva dos animais nunca submetidos a qualquer controle veterinário. Embora tivéssemos tomado medidas de precaução, o vírus contagiou nossos carneiros e nosso gado, reduzindo a produção de leite e causando a morte de alguns animais (OZ, 1978b, p. 53).

Os beduínos não se mostram abertamente desobedientes às leis, mas os crimes perpetrados acontecem à noite e às escondidas:

A escuridão era cúmplice. Esquivos como o vento, passavam pelo povoado e de nada nos valeram os guardas que colocamos de plantão, nem os que mais tarde juntamos aos primeiros para reforçar a vigilância. Saindo por volta da meia-noite para fechar torneiras de irrigação numa gleba distante, montado num trator ou guiando um jipe velho, as luzes dos faróis captavam de repente sombras fugidias de um homem ou de um animal. Um guarda encolerizado decidiu certa noite disparar sua arma e matou apenas um chacal perdido (OZ, 1978b, p. 54).

Os habitantes do Kibutz não se satisfazem com a ineficácia da polícia, "que havia desistido de continuar a investigação" (OZ, 1978b, p. 56), e diante dos prováveis delitos cometidos pelos beduínos, partem para a ação, saindo do seu confinamento, numa ação de guerra contra um vizinho indesejado: "alguns dos nossos jovens propuseram realizar um ataque noturno aos selvagens e dar-lhes uma boa lição numa linguagem 
que realmente entendessem e à qual estavam acostumados" (OZ, 1978b, p. 56). Eles conhecem a lei enquanto os beduínos a ela não se adequariam. Àqueles cabe utilizar-se da lei ou da violência para conter a ação dos beduínos e de seus animais. Como o que realmente importa no kibutz é a produção, assim o ataque contra os beduínos é admissível. Ao final, reúnem-se vários homens para efetuar o ataque. Eles são anti-heróis.

Assim, a história é igualmente incontrolável: como pelo personagem de Franz Kafka, Gregor Samsa, temos compaixão por Gueula, vítima de um estupro - que não está claro se ocorreu. Destaco este trecho, depois do encontro entre Gueula, jovem habitante de Kibutz, com um nômade encontro ao mesmo tempo ameaçador, sensual e repugnante:

No chuveiro, o ralo estava entupido e o banco engordurado. Gueula colocou a roupa limpa sobre o banco de pedra. Não tremo por causa da água fria, não: é de nojo. Que dedos negros, e como agarrou o meu pescoço... E os dentes dele... E as cabras... Magro e pequeno como um menino, mas tão forte. Somente a pontapés e mordidas salvei-me dele. Ensaboar o ventre e tudo o mais. Ensaboar de novo e mais outra vez. Sim, que os rapazes ataquem o acampamento, esta noite ainda, e que lhes arrebentem todos os ossos negros pelo que me fizeram. Preciso sair (OZ, 1978b, p. 64).

$\mathrm{Na}$ vasta obra de $\mathrm{Oz}$, há vários momentos em que o escritor flerta com essas imagens de deformação da realidade tão caras ao estilo expressionista. No conto "O caminho do vento", por exemplo, o kibutz é personificado e a sociedade, predominantemente agrária, torna-se, na narrativa, como um "monstro sagrado": "Vagos raios atacavam a muralha de nuvens que cerrava o horizonte do nascente. Astuto, o dia novo escondia as suas intenções e não dava sinal algum do calor sufocante nele encoberto" (OZ, 1978a, p. 31).

Nesse espaço monstruoso, predominaria o que o crítico Gerschon Schaked chama de baixo instinto, um retorno à natureza, mas de forma fantasmagórica.

Uma luz violeta acende-se nas montanhas a leste. O vento matutino a atiça. Em seguida, raios luminosos rasgam a muralha de nuvens. É dia. Brechas se abrem a dedos de luz. Finalmente, a bola incandescente eleva-se, é atirada à cordilheira de nuvens, e vencendo-a no horizonte oriental, todo deslumbrante, o violeta delicado rendeu-se e se retirou diante do vermelho brilhante e poderoso (OZ, 1978a, p. 31). 
Para Shaked, a narrativa é tensa, sarcástica, grotesca, reflete o conflito de gerações na sociedade israelense, em especial no Kibutz. Nele, não apenas o espaço muda, mas há especificamente uma mudança cultural, constituída a partir do confronto modernização versus valores judaicos, e onde se percebe a esperança por parte do personagem em relação à geração seguinte, sintese da combinação entre as gerações anteriores - a "Geração dos Avós" e a "Geração dos Pais":

A segunda geração cresceu à sombra do nosso empreendimento e por isso ficou complexada. Dialética. Mas a terceira geração, esta constituirá uma maravilhosa síntese e um abençoado produto: seus pais lhes transmitirão a espontaneidade e seus avós, o espírito. Este será um legado magnífico, livre dos efeitos de uma hereditariedade desvirtuada. [...] Nós não permitiremos que a terceira geração seja corrompida por mimos e poesias de damas nobres e decadentes (OZ, 1978a, p. 40-41).

$\mathrm{O}$ personagem de $\mathrm{Oz}$ menciona o escritor Yosef Haim Brenner (1881-1921), um dos pioneiros da Literatura Hebraica Moderna. Destaco também: Shmuel Yosef Agnon (1888-1970), Moshe Smilansky (18741953), David Shimoni (1891-1956), Yakov Fichman (1881-1958) e Hayim Nahman Bialik (1873-1934). A criação de Israel data de poucas décadas, porém, a literatura hebraica moderna já acontece naquele país há mais de um século. As raízes desta nova escrita remontam ao Iluminismo Judaico (Haskalá), na Europa Central do século XVIII, bem como a episódios isolados de escritores que escreviam [mas não falavam] em hebraico.

No final do conto irrompe o personagem arrebatador, personificação do vento: "Um vento, passa entre os ciprestes, à noite, e procura apaziguálos entre o calor e outro. É o caminho do vento, vem, cessa, e novamente vem" (OZ, 1978a, p. 50). O título do conto relaciona-se com Eclesiastes 11:5: "Assim como tu não sabes qual o caminho do vento, nem como se formam os ossos no ventre da mulher grávida, assim também não sabes as obras de Deus, que faz todas as coisas".

"O casamento de Gália" (1970), de A. B. Yehoshua, é um conto estranho, talvez influenciado por Kafka. O personagem é cheio de receios e a morte parece habitar a narrativa. É a atmosfera surrealista de abstração da realidade, de situações grotescas. Nele, o personagem central apresenta ânsia para chegar ao casamento de sua amada. 
O conto possui características expressionistas e se passa no Kibutz Sdot-Or, que em hebraico significa campo de luz. Ele narra sobre uma "suja terminal de ônibus", o motorista retratado como "um monstrengo", "uma coisa empoeirada", um "ser inanimado", que possui na testa um "galho partido" e "mãos de urso", uma "coisa pesada" de "grande boca aberta", enfim uma "abominável criatura", "uma coisa empoeirada que deve ter sido arrancada, com as raízes ainda se agitando, de dentro de uma moita entre as rochas" (YEHOSHUA, 1978, p. 118).

$\mathrm{Na}$ narrativa, o leitor é levado brutalmente aos fatos, como em uma realidade fantasiosa: "Ainda estou me recompondo do meu sonho febril, esfrego os olhos, e já a abominável criatura se deixa cair sobre o assento" (YEHOSHUA, 1978, p. 119).

O personagem remonta a um passado onde se sentira só, mas vira chegar ao kibutz o grupo no qual estava Gália, sempre descrita com a cor azul, como cura para o mal ou esperança: Ela assim é descrita: "Gália delgada, roupa de trabalho azul, olhos de brasa, azuis. Solitária, trazia a inquietação do mundo inteiro contida nos seus ombros estreitos. Despenteada, descuidada, sofrida, porém completa num outro mundo" (YEHOSHUA, 1978, p. 120). E agora, no tempo da narrativa, há o ônibus que o levaria de volta a Gália: "Um belíssimo ônibus azul está parado entre os últimos da fila e seus metais brilham à luz do sol" (YEHOSHUA, 1978, p. 117-118).

O personagem principal em um momento tenta "acordar o chofer que parece congelado" (YEHOSHUA, 1978, p. 122). Ambos, motorista e ônibus, parecem manifestações do mal, de outro mundo, e que impelem um fluxo histórico-geográfico à narrativa, já que somente ele é capaz de atravessar o país e levar o personagem ao encontro de sua amada:

Á máquina está sendo forçada na subida, mas o chofer não alivia a sua marcha. O motor geme, no seu sofrimento, mas ele o sufoca com maldade, injetando mais gasolina. Estupidamente bronco, continua a acelerar a máquina infeliz, que começa a estertorar em agonia, até que por fim morre, no meio a ladeira; seu corpo inanimado recua, descaindo um pouco para a beira do barranco. [...] Ouve-se um murmúrio ao lado da direção e todos nós perscrutamos a escuridão. O pequeno chofer abre aporta ao seu lado e é logo tragado para baixo das rodas do ônibus, para dentro do motor que silenciou (YEHOSHUA, 1978, p. 123). 
Nestas partes, o autor diz: "Eles vão matá-lo... - penso com alegria" (YEHOSHUA, 1978, p. 128), "Ele vai morrer num acidente... ou de uma doença grave... que não será culpa dele... e tu, tu ficarás para mim..." (YEHOSHUA, 1978, p. 131), “- Gália, minha menina... Eles, os três, vão voltar e engravidar as esposas que os esperam. Eu, porém, voltarei para morrer ao lado da oliveira estéril" (YEHOSHUA, 1978, p. 132). E a realidade aparece confusa para o personagem, que se rende aos desígnios do motorista:

Um vulto escuro ergue-se ante mim no caminho. Enxugo os olhos para compreender e vejo, então, o ônibus que me trouxe. Os pés me atraiçoam e voltam a erguer, furiosos, a poeira branca do caminho. Todo confuso, apresso-me em sua direção. Minha cabeça gira e está pesada. Faz tempo que estou caminhando, mas a distância entre nós parece que não diminui. Afinal, entendo, com supressa, que o ônibus estivera se movendo o tempo todo, lentamente, sozinho, sombrio, ao longo da estrada. [...] Com certeza ele conhece bem o caminho, pois o ônibus voa na escuridão, fazendo as curvas com segurança. Às vezes, porém, parece perder o controle ou sua memória o trai. Gira, então, o volante, sem necessidade, rodando para os lados e o grande ônibus, pula em valas e buracos, quase se desmontando (YEHOSHUA, 1978, p. 132-134).

Mas ele é obstinado, e se vê diante de outro personagem de linguagem crua, que encarna a liberdade, para além do bem e do mal:

Ponho a mão, a medo, em suas costas, mas ele nada sente. Continua concentrado na estrada e suas mãos acariciam com força o volante reluzente. [...] Levo as mãos à caixa de engrenagens, tento puxar a alavanca mas ela não me obedece. Arrasto-me até os pedais, que estão embaixo. Os pés dele, entretanto, parecem barras de ferro, curtas e terríveis, sobre sua base. Mordo essas barras de ferro e ele, sem nada sentir, continua fazendo a máquina ruídos acorrer e sacudir pela beira da estrada. [...] O gordo motorista ergueu-se de seu assento e observa-me com toda a sua estatura de anão. Ergue a mão lentamente e retira os óculos escuros, revelando-me sua face. Agora eu a conheço a face do desejo, gorda e vermelha, os olhos escuros e gigantescos nela cravados, que a claridade reveladora mostra até as raízes irisadas; rosto de deus antigo, rasgado por uma boca pequena (YEHOSHUA, 1978, p. 134). 
O motorista, além de se mostrar uma fortaleza, também onisciente:

Ele mede-me atentamente. Descompõe-me em fragmentos, sugame para o abismo de seus olhos metamorfoseados, até que eu me humilho, pequeno e insignificante. Subitamente ele sente piedade por mim. Inclina o corpo pesado, pega no meu braço mirrado e ergue-me, assustado e sujo, do chão. Agora aproximo-me dele, vejo sua testa enorme lavrada de miríades de rugas vermelhas e pequenas. Fita-me com admiração por muito tempo, até que sua voz profunda brame, triturada:

- O casamento de Gália terminou (YEHOSHUA, 1978, p. 135)!

Assim, percebe-se a existência de personagens sarcásticos e irônicos nas obras de Oz e de Yehoshua, além da multiplicidade de estilo, como surrealismo e expressionismo. Tanto Gueula, personagem de "O nômade e a víbora", quanto o personagem principal de "O casamento de Gália" não são heróis. Gália deseja vingança e morte, assim como o outro anima-se com a surra que marido de sua amada leva. Os personagens principais mostram-se vítimas e algozes, violentos, ciumentos, individualistas e introspectivos. Este é um sentido de personagem moderno que demonstra a crise do homem no século XX.

A partir de Benjamin e sua leitura do expressionismo alemão percebia-se o advento do novo homem, quase bíblico/judaico. Aqui, nos contos, percebe-se a crise do homem do kibutz, do ideal cidadão israelense, ou mesmo do conceito de nação. No contexto dos escritores da Geração do Estado rompe-se com o ideal nacional de formação do caráter do povo. Nesse sentido, essa geração tinha todas as armas e instrumentos para tornar realidade uma nova literatura de uma nova época, de um novo homem e de novos modos de relações sociais. Aqui não se evidencia o pessimismo de Benjamin: o expressionismo, desencadeado pelas circunstancias históricas daquele momento, expressou de forma subjetiva a natureza e o ser humano, dando primazia à expressão de emoções e sentimentos na representação da arte, em detrimento à simples descrição objetiva da realidade.

Nos três contos, o cenário é o kibutz, local em que o homem está integrado à natureza. É marcante a relação entre "natureza" e "homem", havendo duas posturas diferentes, uma técnica ou exterior, e outra religiosa ou interior. A primeira postura foi evidenciada no final de "O nômade e a víbora", onde o ódio resultaria na guerra contra os beduínos. O narrador elucida e critica a estrutura do kibutz e mesmo a sociedade, 
alinhando-se à ideia que Benjamin tem do artista: informar com crítica, liberto da alienação do homem moderno. Em "O casamento de Gália", a ação é linear, apesar de o motorista ser uma espécie de personagem paralelo, fora do espaço-tempo tradicional. Ademais, o desfecho da obra é deixado em aberto, o mesmo ocorrendo em "O nômade e a víbora". Ambos fazem relações com o real, com a lógica real, a verossimilhança. Estas são características que Benjamin propôs em sua perspectiva de romance: estranhamento e distanciamento. O narrador é levado a uma suprarrealidade, realidade para além. A oralidade está presente entre os beduínos e o kibutz é agente. Há questões existenciais e egocentrismo. Benjamin propôs também que a perspectiva da narrativa moderna passara a ser múltipla. Em "O caminho do vento", há certo distanciamento e estranhamento, mas ainda assim um narrador onisciente. Assim como no Expressionismo, esses contos não dão um sentido à existência, pelo contrário, proporcionam angústia e alienação.

Benjamin formulou a teoria das "formas primordiais" na arte, baseado na leitura de Goethe e produziu um conceito de tempo presente na arte. Ele encontrou as "formas primordiais" da arte no drama barroco alemão no século XVII e XVIII, persistindo até o expressionismo alemão da década de 1920 (BENJAMIN, 1984). Desse modo, por influência da ótica benjaminiana os contos aqui analisados podem ser manifestações de arte produtora de pensamento. Os autores aqui estariam rompendo com convenções sociais e literárias, como normalidade e anormalidade, principalmente as israelenses. Aqui, com $\mathrm{Oz}$ e Yehoshua, não há mais a nostalgia que levou Iehudá Halevi a escrever "Meu coração está no Oriente enquanto eu resido no meu extremo ocidente" (GUINSBURG, 2009, p. 23 apud GLASSMAN, 2007). Os escritores não estão mais no exílio, apegados às raízes históricas e ao Segundo Templo, e principalmente a Jerusalém, como se este passado fosse o "elixir da juventude" (GUINSBURG, 1966, p. 5). A experiência surrealista enfraquece a realidade empírica, pois o mundo é um mundo de coisas sonhadas, o leitor é imerso em uma realidade onírica. Assim os contos romperam com barreiras ideológicas sionistas.

As reflexões sobre os contos de $\mathrm{Oz}$ e Yehoshua, lidos à luz de Walter Benjamin e de suas proposições sobre a vanguarda europeia, se revelaram apropriadas, no entanto, pode-se levantar a seguinte questão: trata-se, de fato, de contos com características vanguardistas, ou seriam estes contos "pós-modernos"? 


\section{Referências}

BENJAMIN, Walter. Magia e técnica, arte e política: ensaios sobre literatura e história da cultura. Obras Escolhidas: v. 1, 7. ed. São Paulo: Brasiliense, 1994.

BENJAMIN, Walter. A crise do romance. In: Documentos de cultura. Documentos de barbárie: escritos escolhidos. Seleção e apresentação de Willi Bolle, trad. Celeste Ribeiro de Sousa et al. São Paulo: Edusp; Cultrix, 1986. p. 126-129.

BENJAMIN, Walter. Escritos sobre mito e linguagem (1915-1921). Organização, apresentação e notas de Jeanne Marie Gagnebin; tradução de Susana Kampff Lages e Ernani Chaves. São Paulo: Duas Cidades, 2011.

BENJAMIN, Walter. Infância em Berlim por volta de 1900. Obras escolhidas, v. II. Trad. José Carlos Martins Barbosa. São Paulo: Brasiliense, 1987. p. 71-142.

BENJAMIN, Walter. Origem do drama barroco alemão. Trad. Sergio Rouanet. São Paulo: Brasiliense, 1984.

BENJAMIN, Walter. Passagens. Trad. Irene Aron, Cleonice Paes Barreto Mourão e Patrícia de Freitas Camargo, 2006.

BENJAMIN, Walter. Rua de mão única. Obras escolhidas. v. II. Trad. José Carlos Martins Barbosa. São Paulo: Brasiliense, 1987. p. 9-70.

BEREZIN, Rifka (Org.). O novo conto israelense. Trad. Nancy Rozenchan, Rifka Berezin, entre outros. São Paulo: Símbolo, 1978.

GUINSBURG, Jacó. A literatura hebraica no Estado de Israel. WebMosaica, Porto Alegre, v. 1, n. 1, p. 23-32, 2009.

MINTZ, Alan L. (Ed.). Reading Hebrew literature: critical discussions of six modern texts. New England: UPNE, 2003.

OZ, Amós. O caminho do vento. In: . O novo conto israelense. Trad. Nancy Rozenchan, Rifka Berezin, entre outros. São Paulo: Símbolo, 1978a.

OZ, Amós. O nômade e a víbora. In: . O novo conto israelense. Trad. Nancy Rozenchan, Rifka Berezin, entre outros. São Paulo: Símbolo, $1978 b$. 
PINSKER, Shachar. Literary Passports: The Making of Modernist Hebrew Fiction in Europe. Stanford: Stanford University Press, 2010.

PRESSLER, Günter Karl. A idéia da vanguarda no ensaio O Surrealismo. O último instantâneo da inteligência européia e sua repercussão na crítica alemã. Pandaemonium Germanicum, São Paulo, n. 2, p. 119-140, 1998. ROSENTHAL, Herman Peter. Haskalah. In: WIERNIK, Singer Isidore; ALDER, Cyrus (Ed.) et al. The Jewish Encyclopedia. New York: Funk and Wagnalls, p. 1901-1906. v. 8.

YEHOSHUA, Avraham B. O casamento de Gália. In: . O novo conto israelense. Trad. Nancy Rozenchan, Rifka Berezin, entre outros. São Paulo: Símbolo, 1978.

Recebido em: 7 de outubro de 2018 Aprovado em: 8 de novembro de 2018 
